\title{
OS CONTOS DE FADAS: ESTRATÉGIA PEDAGÓGICA PARA MITIGAR ESTEREÓTIPOS FEMININOS
}

\author{
LUCIANA FeRnANDES CIMETTA \\ ANDREZA MARQues de CASTRO LeÃo \\ Universidade Estadual Paulista (UNESP), Araraquara, São Paulo, Brasil
}

\begin{abstract}
Resumo: A sexualidade é construída a partir de padrões de comportamento e costumes da humanidade ao longo da história, e por diversos fatores resulta em sua liberação ou repressão. Os contos de fadas por sua vez, provenientes da oralidade e recontados ao longo dos séculos colocam as mulheres constantemente de forma inferior perante os homens, naturalizando a vulnerabilidade feminina. Em vista disso, este artigo de cunho bibliográfico buscou conhecer, descrever e problematizar o que os estudos científicos dizem acerca do uso dos contos no ensino médio, procurando analisar sua utilização como estratégia pedagógica para mitigar os estereótipos de inferioridade feminina e outros preconceitos. Confirmou-se, assim, a assertividade dessa abordagem, uma vez que se pode transmitir valores, reforçar ou criticar paradigmas e questões de gênero.
\end{abstract}

Palavras-chave: Contos de Fadas. Sexualidade. Estereótipo. Preconceito.

\section{INTRODUÇÃO}

A sexualidade é fruto de uma construção, segundo os padrões de comportamento, costumes e pensamentos da humanidade ao longo da história. Isso ocorre porque o cenário ao qual a sexualidade está situada compõe-se de diversos fatores, sendo esses culturais, econômicos, políticos ou outros que exercem alguma influência sobre a sociedade. Os contos de fadas, por outro lado, são provenientes da tradição oral e trazem consigo traços culturais que permeiam não só o patrimônio e história de um povo, como também a nossa própria trajetória.

Por esse motivo, este estudo busca abarcar a representação das relações e desigualdades de gênero nessa literatura, que inferiorizam o feminino em relação ao masculino, pois por meio das situações encontradas nos contos de fadas o machismo, 0 sexismo, a discriminação e outros aspectos que perpetuam estigmas negativos estão comumente presentes. Isso em si pode ser empregado no âmbito educacional, uma vez que possibilita ao professor do ensino médio utilizar os contos de fadas como ferramentas para uma análise crítica e reflexiva da sociedade. 


\section{AS RELAÇ̃̃ES DE GÊNERO E OS CONTOS DE FADAS}

Maria José Garcia Werebe (1998) aponta que a consideração da sexualidade voltada exclusivamente à reprodução originou-se também de uma visão moralista, responsável igualmente por alimentar os interesses políticos ao longo do tempo, em praticamente todas as sociedades. 0 moralismo, no que Ihe diz respeito, devido às influências religiosas, condenou tanto o desejo sexual quanto o prazer, culminando na estigmatização de ambos.

Quando nos deparamos com a delimitação do comportamento sexual, a autora sugere que a mesma se apresenta de maneira problemática, haja vista que o limite entre o sexual e o não-sexual encontra-se numa linha tênue, havendo uma certa dificuldade ao distinguirmos ambas as noções.

Os discursos religiosos, por sua vez, condicionavam o comportamento humano feminino à privação de seus impulsos e desejos sexuais em troca da ausência de sentimentos de culpa e transgressão. Segundo Augustini (2015) a ideologia presente nesses discursos delimitou o comportamento humano, especialmente o feminino, na direção contrária à vivência desses impulsos e desejos sexuais. 0 sentimento de culpa sempre esteve associado a qualquer tentativa de experiência da própria sexualidade, como nos mostra a pesquisadora, visto que quando esse sentimento ultrapassava seus sentidos morais, como o casamento e reprodução, resultaria em transtornos psicológicos, sociais e morais para as mulheres.

Em oposição à concepção anterior, Augustini (2015), por meio de sua interpretação da obra de Freud, acrescenta que o psicanalista em sua investigação sobre a sexualidade humana defendeu a sublimação da energia sexual para se alcançar conquistas no aspecto cultural. Ela analisou também as contribuições dos estudos de Wilhelm Reich, que evidenciavam a ausência da necessidade de sacrifício ou repressão da sexualidade humana por outras sociedades.

Quanto à pesquisa científica voltada a sexualidade, essa se iniciou recentemente, baseando-se inicialmente na observação apenas de pacientes e não da população em geral, o que ocorreria posteriormente por meio de outros estudos. Segundo Werebe (1998), esses estudos começaram na Europa, tendo como expoentes as pesquisas de Krafft-Ebing, Havelock Ellis e Freud. Essas obtiveram uma vasta repercussão internacional e foram responsáveis pela origem de diversos outros estudos posteriores.

No Brasil, a preocupação com a sexualidade data do início do século XIX, visto que estudos médicos e higienistas nessa área tornaram-se necessários nesse período a fim de se combater a masturbação e doenças venéreas. Como indica Leão (2009) a educação sexual, mais especificamente nas décadas de 20 e 30, passa a ser evidenciada também nas escolas através de educadores e médicos que buscam a melhoria da saúde da população, além de instigar as famílias a também participarem desse processo. Assim sendo, nesse período observa-se que a sexualidade era debatida com base na saúde pública e a educação pautava-se no combate às práticas sexuais consideradas inapropriadas. No entanto, a pesquisadora evidencia que ao mesmo tempo em que mui- 
tos autores propagavam o controle do sexo baseado no moralismo daquele período, outros 0 associavam a um olhar mais natural e libertador.

Nas décadas de 1930 a 1950, a igreja exerceu grande poder sobre o sistema educacional, repreendendo a educação sexual e associando discursos sobre a sexualidade relacionados à punição. Isaura Guimarães (1995) aponta que, nos anos 60, houve algumas tentativas de inserção dessa educação no Brasil, porém com o Golpe Político-Militar de 1964 , tais medida foram censuradas.

Apenas com o início dos anos 80 o país reformula seus sistemas de ensino estaduais e municipais, devido à abertura política desse período. Neste momento, a educação sexual cresce como parte das práticas institucionais em diversos estados brasileiros, visto que alcança diferentes formas de discursos, conquistando seu espaço nas mídias de massa e atingindo os interesses sociais da população.

No que condiz às questões relacionadas ao gênero, Guimarães (1995) aborda em sua obra, entre outros aspectos, as diferenciações entre os termos gênero e sexo. Sendo assim, para ela a distinção entre os dois verbetes se faz fundamental, uma vez que para o senso comum, ambos seriam sinônimos. Assim, para a autora a palavra sexo associa-se à diferença biológica e compreende também as diferenças de anatomia e fisiologia, por exemplo. Já gênero é responsável por caracterizar tudo que corresponde ao masculino e feminino.

Guacira Lopes Louro (1997), por sua vez, também trata dessa temática em seu livro intitulado Gênero, sexualidade e educação. Uma perspectiva pós-estruturalista. Para a autora, quando direcionamos o foco para o social, não há a intenção de negar a constituição do gênero sobre corpos sexuados, mas sim ressaltar sua construção, tanto social quanto histórica, atrelada à biologia.

Dito isso, quando voltamo-nos especificamente à dominação e repressão masculinas, Guimarães (1995) ressalta que alguns sinais do período neolítico nos indicam que a mentalidade daquela sociedade apresentava-se de forma mais igualitária, ou seja, com a ausência de hierarquias e a harmonia na convivência feminina e masculina. Ela presume ainda que a falta de elo entre a gestação e as relações sexuais nessa época contribuíram para a atmosfera mais pacífica. Dessa forma, esse predomínio masculino desencadeou-se a partir da compreensão pelo homem de seu papel gerador de vidas, apoderando-se como as mães de seus filhos. A família patriarcal desenvolveu-se então progressivamente, associada ao acúmulo de poder e autoridade centrada na figura masculina.

Os valores universais e alternativos no que the dizem respeito se relacionam reciprocamente, culminando na possível liberação sexual ou repressão e aprisionamento da mesma. Dessa forma

O sistema de normas, regras, leis e valores explícitos que uma sociedade estabelece no tocante a permissões e proibições nas práticas sexuais genitais (mesmo porque um dos aspectos profundos da repressão está justamente em não admitir a sexualidade infantil e não genital). Essas regras, normas, leis e valores são definidos explicitamente pela religião, pela moral, pelo direito e, no caso de nossa sociedade, pela ciência também (CHAUÍ, 1984, p. 77). 
A construção dos papéis masculinos e femininos se constitui da mesma forma. Esses se compõem por padrões e regras estabelecidos por uma sociedade, e essas normas designam comportamentos e maneiras de relacionamento para seus membros. Segundo Guimarães (1995), por meio da absorção desses papéis cada indivíduo possivelmente conheceria o que se considera adequado tanto para um homem como para uma mulher e, dessa forma, agiria da maneira considerada correta pelo todo. Contudo, ela nos indica que essa concepção apresenta-se de maneira reducionista, uma vez que impossibilita a análise dos indivíduos e suas relações interpessoais.

Nesse sentido, Werebe (1998) repensa a importância da educação sexual e complementa sobre o poder de imposição de cada sociedade em relação às regras determinadas acerca da sexualidade. Sentimentos de medo e culpa relacionados ao sexo originam-se nos tabus estabelecidos pelo homem à sua sensibilidade. Diante disso, a animalidade desenfreada se opõe a um princípio humanizador. Isso se justifica, pois a sociedade humana distingue-se dos animais quanto à sua capacidade de erotização e recusa dos instintos.

Tais proibições e aprovações podem ser tanto interiorizadas pela consciência através de questões sociais como a educação, ou afastadas por meio da transgressão, já que trazem consigo sentimentos de sofrimento. Dessa forma, o sexo, considerado hipoteticamente biológico e natural, sofre alterações em relação ao seu sentido e função ao ser transposto para o plano social e cultural.

Os estudos da sexualidade, por sua vez, apontam as ambiguidades, pois ao invés de se diminuir a repressão determinada ao longo do tempo, ela tem se intensificado. A sociedade atua, assim, como fortalecedora da repressão e moral conservadora, levando a comportamentos voltados à clandestinidade e ao segredo quanto às práticas sexuais.

Como exemplo disso, Chauí, ao analisar as teorias de Freud, assinala que ao mesmo tempo em que ele revoluciona os conhecimentos relacionad os à sexualidade, em suas últimas obras conclui que a humanidade necessita da repressão sexual. Ainda que considere conveniente a diminuição de preconceitos sexuais, para ele as pulsões sexuais podem ter aspectos destrutivos e agressivos que atrapalhariam a ordem social.

Além disso, seguindo a análise de Augustini (2015), numa sociedade que constrói identidades, aqueles que fogem ao padrão considerado normal aprisionam-se em seu sujeito distanciando-se de sua real identidade. Confirma-se, dessa maneira, que as identidades sexuais formam-se através do social.

Ao longo dos tempos a sociedade vem se mostrando desigual em relação ao tratamento dado para homens e mulheres, e reflete até os dias atuais o resultado dessas atitudes no cotidiano, tornando esse contraste banal. Muitos mecanismos atuam para esse resultado final, preservando essa estrutura social.

Em sua obra, Louro (1997) aborda as práticas educativas voltadas à produção das desigualdades sexuais e de gênero, e suas relações com traços sociais como raça, classe e etnia. Ela revisita também as teorias elaboradas pelos estudiosos feministas, analisando profundamente as repressões sociais e desigualdades, além de sugerir a quebra do pensamento dicotômico, ou seja, o feminino em oposição ao masculino. Dessa forma, 
busca a problematização, dando espaço às diversas combinações de gênero, sexualidade, classe, etc.

Louro (1997) mostra que a inferioridade direcionada às mulheres apresenta-se através de diversas ações com 0 intuito de oprimi-las. A autora argumenta também que essas desigualdades são observadas em diversos períodos da história, o que reforça a importância da identificação dessas atitudes.

Nesse sentido, é evidente a importância da utilização dos contos de fadas no ensino médio, pois como trataremos mais à frente, o mesmo nos possibilita estabelecer paralelos entre a representação feminina nessa literatura e a sexualidade. Isto se faz possível, uma vez que, devido à sua atemporalidade, esse tipo de literatura poderá reforçar ou criticar preconceitos, paradigmas e questões de gênero, além de exprimir e transmitir valores.

Assim sendo, o hábito de contar e ouvir histórias já nos acompanha desde a antiguidade, visto que, por meio da tentativa de explicar fenômenos desconhecidos pela ciência, elementos fantásticos e mágicos eram inseridos nas narrativas. Dessa forma, havia a junção do prazer à suposta solução dos mistérios da natureza por meio das histórias contadas. Esse ato de prazer funcionava como uma fuga aos hábitos cotidianos.

A literatura, por sua vez, atuaria como expressão do desejo e constante domínio sobre a vida, ansiada pelos homens de todos os tempos (COELHO, 1991). Fábulas, parábolas, mitos, contos maravilhosos e os contos de fadas, por exemplo, fazem parte matéria narrativa que guarda em si esse saber fundamental almejado pela humanidade. Contudo, nos aprofundaremos respectivamente neste último, por estabelecer relações relevantes com as desigualdades femininas citadas.

Vladimir Propp (2002), através de seu método estruturalista, concluiu por meio da análise de algumas narrativas que todas possuíam em comum a sequência de ações e funções narrativas. Além disso, ele se questionou sobre a possível origem semelhante desses contos folclóricos, nos quais constatou que sua fonte encontrava-se nas práticas comunitárias dos povos primitivos. Essas, segundo sua análise, comportavam os ritos de iniciação sexual e representações de vida após a morte.

Propp (2002) nos indicou ainda que, devido à necessidade de sigilo para o êxito dos rituais de iniciação sexual ou de passagens para outro mundo, a opção encontrada para sua conservação deu-se através dos mitos. Essas narrativas geralmente eram utilizadas após a execução dos rituais, tornando-se parte essencial deles. Para tanto, permitia-se a transmissão de ensinamentos dos mais velhos aos mais novos.

À vista disso, os mais velhos passavam aos iniciantes o que lhes ia sucedendo, mas referindo-se ao ancestral fundador daqueles costumes. Essas narrativas faziam parte dos rituais, contudo não eram divulgadas, atuando como um segredo entre o iniciador e 0 iniciado. Desse modo, transformavam-se em mitos transmitidos como instrumentos indispensáveis para elucidar a vida tanto individual como social à comunidade.

Para Propp (2002), o começo da transformação do mito ao conto deu-se a partir da desassociação entre a história e sua narração comum aos rituais, ou seja, momento esse onde o mito passou a se alterar para o conto popular. Com o tempo, sua narração converteu-se para ambientes comuns e públicos, perdendo o caráter sagrado e adotando o sentido de simples histórias de entretenimento. Por meio dessa ausência de funções 
religiosas, o conto se espalhou e começou a receber contribuições significativas da sociedade.

Mendes (2000) nos mostra que essa separação entre ambos pode ter ocorrido devido a necessidades históricas ou de forma artificial acelerada por meio da chegada dos europeus, através da cristianização dos índios e a mudança de tribos para terras mais pobres, por alterações no modo de vida, etc.

Propp (2002) elaborou o conceito de mito, considerando toda narrativa que trata sobre deuses e outros seres divinos e em que um povo crê. Além disso, nos indica que tanto o mito quanto o conto se distinguem pela função social: a função social do primeiro depende do grau de cultura de um povo.

Segundo suas análises, considerou também que os contos maravilhosos possuem características peculiares, diferenciando-os quando nos referimos através do verbete "contos" para todo tipo de narrativa. Entre essas características o autor cita, por exemplo, um dano ou prejuízo causado, ou o desejo de possuir algo, culminando na partida do herói, encontro com o doador que Ihe dá um recurso mágico ou um auxiliar mágico para encontrar o que deseja.

Sobre isso, Dianna Corso e Mário Corso (2006) complementam que os contos de fadas, de modo geral, devem abarcar elementos diferenciados, extraordinários e que surpreendam, visto que o verbete "maravilhoso" advém do latim e tem como significado algo admirável, extraordinário.

Por sua vez, Jung (1998), através de uma perspectiva psicológica, busca compreender nosso universo interior e retoma o sistema simbólico humano a fim de estabelecer a relação entre a compreensão dos símbolos e a consciência da natureza humana. A partir daí o psiquiatra compreende que o comportamento humano e suas formas são o esquema principal da psique humana, ou seja, o inconsciente coletivo. Dessa maneira, concluiu que os "sonhos arquetípicos" são representados pelos mitos, isto é, os sonhos de todos os homens contam sobre sua origem e evolução da espécie.

Seguindo esses estudos, os arquétipos estão cheios de emoção, isto é, energia. Essa energia, portanto, permite-Ihes intervir no comportamento, tanto individual quanto coletivo, e assim criar mitos, religióes e filosofias. Mendes (2000, p.35) destaca que "Um arquétipo é uma forma de pensamento ou de comportamento, um símbolo das experiências humanas básicas, que são as mesmas para qualquer indivíduo, em qualquer época e qualquer lugar".

As figuras arquetípicas do inconsciente coletivo estão presentes nos mitos e contos de fadas, mas não são notadas diretamente. Por isso, essas imagens são preservadas e perpetuadas ao longo da história, valorizando os contos de fadas desde a Antiguidade.

Por sua vez, os seguido res freudianos consideravam que tanto os sonhos quanto os contos representavam impulsos reprimidos da infância, ou seja, possuíam em suas características estruturais elementos relacionados às tensões ligadas aos desejos e impulsos sexuais contidos durante a infância.

Campbell (1990) em seu livro O poder do mito analisou a relação entre mitos e sonhos, concluindo que ambos expressavam-se de forma semelhante e com o mesmo ti- 
po de linguagem simbólica. Para ele, os mitos atuavam como canais para a espiritualidade humana, isto é, conduziam o olhar para nosso interior. 0 autor considerou que os mitos de diversos povos apresentavam imagens e problemas semelhantes, pois sempre trataram de diversas situações de vida e sobre as relações sociais, sejam em grupos ou individuais. Assim sendo, por meio deles, pode-se notar que a maneira como o homem primitivo enfrentava tais circunstâncias assemelhava-se ao homem moderno.

Através de pesquisas, tanto no campo linguístico quanto na psicologia, pode-se chegar às raízes do conto popular e também aos deuses e heróis presentes na mitologia. As primeiras entidades divinas idealizadas pelo homem eram femininas, representando a Lua, protetora das colheitas e deusa do amor e fertilidade. Entre as figuras mais conhecidas no universo agrário da antiguidade estão Nut, deusa egípcia do céu, e sua filha, fruto da união com Geb; Ísis, no Egito; e Istar, deusa da guerra na Mesopotâmia.

Mendes (2000) por meio da abordagem da obra Campbell (1990) elucidou que, em alguns sistemas religiosos, a divindade suprema era representada por uma deusa, como na mitologia primitiva por meio da Mãe-Terra. Dessa maneira, todas as faces representantes da deusa Grande Mãe correspondiam à manifestação da multiplicidade de figuras benévolas e malévolas, propagadas ao longo da história da humanidade, seja por meio dos rituais religiosos ou dos mitos. Essa reprodução simbolizava o poder do Grande Feminino de gerar e destruir através dos fenômenos naturais, ou seja, seu culto baseava-se na harmonia com a natureza, visto que essa encarnava tanto a vida quanto morte.

Assim sendo, todas essas representações constituíam o corpo da Deusa, preservando-a no inconsciente coletivo e revelando-se tanto nos sonhos, como nas culturas e na literatura posteriormente. Contudo, as coletâneas de narrativas relacionadas aos povos primitivos não continham as condições em que tais narrativas eram contadas, apenas os textos em si. Algumas exceções nos dão alguns detalhes sobre a maneira de realização desse ato de contar histórias.

Mendes (2000) nos indica ainda que, após a invasão dos semitas e indo-europeus, aproximadamente no quarto milênio, as mitologias com orientação masculina passaram a ganhar espaço. A cultura dos dominadores fixou-se, fazendo assim com que a DeusaMãe deixasse sua força ao Deus-Pai, por exemplo. Assim, institui-se a sociedade patriarcal.

Ao longo dessas concepções, observa-se então que o preconceito à figura feminina da Grande Deusa demonstrou-se de forma ainda maior entre os hebreus. Isso justifica a convivência na mitologia grega de deuses e deusas, mesmo que Zeus fosse o Deus-Pai naquele período. Mendes (2000) compreende também que na Idade Média a imagem da Grande Deusa ressurgiu, através da devoção à Mãe de Deus e coincidiu com a propagação dos contos populares. Nesse mesmo período as fadas passaram a atuar como herdeiras das deusas primitivas, representando-as nas narrativas.

Logo, os contos de fadas são valorizados desde a Antiguidade, pois para muitos contam o esquema básico da vida do homem, abarcando todos os ciclos enfrentados desde a infância à vida adulta. Os arquétipos do inconsciente estão presentes, mas não são notadas diretamente, e por isso preservam-se e perpetuam-se ao longo da história.

Quanto aos registros sobre o primeiro conto de fadas, Cashdan (2000), considerou o mito de Eros e Psiquê como o precursor. Para Mendes (2000), contos como a Bela Adormecida, Branca de Neve e Cinderela possuem indicativos da influência desse 
mito, já que a rivalidade pela beleza permeia tais histórias e ocorre entre a nora/enteada e sogra/madrasta.

A história de Psiquê encontra-se no livro $O$ asno de ouro de Apuleio (s.d.). Psique, devido à sua beleza, desperta a inveja de Vênus e, por esse motivo, a disputa pelo poder feminino circunda os fatos centrais dessa narrativa. Erich Neumann (1990) revisita essa narrativa, partindo dos conceitos junguianos. Assim, para ele o mito de Eros e Psiquê reflete a evolução da alma da mulher, centro da psicologia feminina e concebida através da cultura matriarcal mediterrânea pré-grega, responsável por influenciar Platão e Apuleio, por exemplo.

Para Mendes (2000), que também trata dessa narrativa em seu livro, há a presença da disputa entre o poder divino e humano femininos, representada por Vênus e Psiquê. Para tanto, o conflito entre a mulher madura e a jovem se faz presente, visto que Psiquê desafia o poder da Grande Mãe (Vênus), já que é mais bela que essa e casa-se em segredo com um deus, sendo castigada devido a tais circunstâncias.

Como nota-se, o ato de contar e ouvir histórias era comum na Idade Média, porém não se dirigia exclusivamente às crianças, visto que a infância era inexistente nesse período. Com a passagem do século XVII ao XVIII esses contos passaram a restringir-se à apreciação apenas das crianças e do povo campestre, dando espaço também ao surgimento da literatura infantil.

Ao retomarmos acontecimentos anteriores, quando Luís XIV fez de Versalles sua morada oficial, a vida da sociedade nobre e burguesa alterou-se. No entanto, Paris ainda se manteve como o centro do reinado, uma vez que abrigava todas as instituições sociais e culturais, os estabelecimentos comerciais, a imprensa, etc. Além disso, a cidade acomodava os salões literários, responsáveis pela influência social dos contos populares e onde desenvolvia-se o "preciosismo", conhecido como barroco francês. Nas reuniões produzidas nesses espaços haviam regras relacionadas ao conteúdo e forma linguística das obras produzidas. As mulheres também participavam desses encontros e sobressaiam-se neles, porém tal destaque não se expandia além dos salões.

Perrault frequentava os salões literários, acatando as regras e a moda que ali eram estabelecidas quanto à produção literária. Ele também defendia as mulheres que ali participavam devido aos ataques recebidos por outros escritores, mas em contrapartida apresentava em sua produção literária elementos implícitos que indicavam uma posição contrária a elas. Mendes (2000) assinala ainda que ele possivelmente colheu nesses salões a ideia dos contos publicados em prosa, visto que contar e escrever histórias era modismo nesses locais.

Vemos então que além da influência que estes contos exerciam na infância, a presença de elementos mágicos também serviu aos interesses das classes dominantes compostas pelos adultos, uma vez que se utilizavam dessa literatura como forma de disciplinar os mais jovens moralmente. A moral atuava então no sentido de auxiliar a criança mediante sua convivência em sociedade, ensinando-a como se portar conforme as expectativas de todos à sua volta. Essa classe via no sistema educacional um caminho para perpetuar sua ideologia, dando lugar à moralidade presente nos contos. 
Por meio da reutilização, tanto da literatura originada na adaptação dos clássicos que compunham o acervo cultural da classe dominante, como dos contos de fadas que circulavam entre o povo dominado, a moral foi utilizada na educação elaborada pelo capitalismo burguês com o objetivo de atingir a nova sociedade que se fixava no século XVI.

Sendo assim, mediante a ascensão social da burguesia, o conceito de infância passou a existir. Mendes (2000), através de sua interpretação da obra de Zilberman, nos indica que a publicação da coletânea de Perrault em 1697 desencadeou esse processo, fazendo com que os contos, antes compostos pela rejeição do camponês às condições de trabalho, passassem a transmitir valores que limitavam esse povo a um determinado papel em sociedade.

O escritor ainda nos mostra que Perrault também antecipou-se às análises psicanalíticas de Freud, repletas de pensamentos pedagógicos e moralistas, pois adicionou em sua literatura a moral e enxergava nos "Contos da Mamãe Gansa" ferramentas para aprimorá-la na educação infantil, por meio da utilização ideológica de elementos representados por bruxas e fadas.

As fadas, por meio das concepções vistas anteriormente nesta pesquisa, têm o papel de transmitir a magia e o sonho às crianças para que se possam suportar as adversidades da vida em meio a papéis sociais determinados por poderes mágicos imutáveis. Além disso, as fadas mantêm nos contos o poder feminino das comunidades primitivas. Contudo, os arquétipos femininos e masculinos também funcionavam como ferramentas para retratar a moralidade da época, porém reforçando o papel de empoderamento masculino em detrimento da suposta vulnerabilidade feminina.

Dessa forma, é notório que os contos não se apresentam linearmente, pois sempre se adaptaram às novas condições sociais, todavia preservando a base de suas narrativas. Observa-se, também, por meio de uma análise mais aprofundada, a presença de diversas questões relacionadas ao preconceito, gênero e paradigmas impostos pela sociedade. A construção do gênero, por exemplo, pode ser favorecida ou não por meio dessa literatura, através das visões de mundo que ali são expressas e, muitas vezes, na maneira como os personagens que a compõem se mostram diante dessas narrativas.

Após Perrault, a literatura infanto-juvenil começou a dar seus primeiros passos no mundo. No século XVIII, cem anos depois na Alemanha, Jacob e Wilhelm Grimm, os irmãos Grimm, buscavam fundamentar seus estudos filológicos sobre a língua alemã, e para isso coletavam narrativas das camponesas e contadores de histórias, podendo assim, a partir de tais elementos linguísticos, estudar a respeito dessa língua. Ambos eram integrantes do Círculo Intelectual de Heidelberg e atuavam como filólogos, folcloristas e estudiosos da mitologia germânica.

Suas investigações acabaram resultando num primeiro livro não voltado às crianças. No entanto, influenciados pelas ideias cristãs da época e se rendendo à polêmica causada por certos intelectuais, posteriormente retiraram a violência e maldades direcionadas às crianças e originaram a segunda edição de seu livro. Com a suavização dessas narrativas e o respeito ao processo de compreensão infantil, o triunfo desses contos deu espaço ao surgimento do gênero Literatura Infantil.

Mais à frente, o dinamarquês Hans Christian Andersen considerado por muitos como o "pai da literatura infantil", de forma distinta dos demais, escrevia seus contos dire 
tamente às crianças. Segundo Coelho (2012), o escritor estava a par dos ideais românticos daquele período - século XIX, início do Romantismo - exaltando a sensibilidade, a fé-cristã e os valores populares, e por isso passou a falar com o público infantil através do coração.

Nesse sentido, sua literatura abrigava a realidade cotidiana e, por esse motivo, apresentava geralmente finais tristes e trágicos. Outro ponto a se considerar é o fato de Andersen aplicar um tom de nostalgia aos seus contos, e isto se explica, pois vivenciou grandes contrastes em sua infância por meio de um passado pobre. Assim, nota-se também a forte presença de seus sentimentos e alma, evidenciando a magia contida em sua narrativa.

\section{O PAPEL DA ESCOLA EDO PROFESSOR: USO DOS CONTOS DE FADAS E AS RELAÇÕES DESIGUAIS}

Após esse breve panorama sobre a origem dos contos de fadas e sua composição, este estudo encaminha-se para a análise dos elementos que evidenciam as desigualdades abordadas. Partindo desse ponto, Mendes (2000) examina os arquétipos femininos presentes na obra Contos da Mamãe Gansa, de Charles Perrault, uma vez que o escritor deixou rastros de suas crenças e valores em sua produção literária.

Por meio dessas visões, as mulheres eram colocadas constantemente num processo de inferioridade perante os homens, e em diversas versões foram ensinadas a esperar passivamente pela felicidade ou salvação, naturalizando a hegemonia masculina branca economicamente favorecida, e ao mesmo tempo subalternizando o lugar do feminino em nossa sociedade. Observa-se também a presença do racismo e preconceito, já que fundamentos do mito da democracia racial e do branqueamento estão em seu conteúdo.

Tais contos abrigam a dualidade entre o masculino e feminino, onde há a perpetuação da subordinação feminina, além da imposição de papéis e atitudes consideradas corretas pela moral. 0 percurso da mulher na sociedade atrela-se continuamente ao preconceito, discriminação e paternalismo, como já observamos na presente pesquisa. Dessa forma, legitima-se o papel da submissão feminina, onde mulheres são sempre associadas às atividades de mãe ou dona de casa.

Chauí (1984) discorre também sobre os contos de fadas e as dualidades apresentadas nas funções sociais femininas e masculinas, reforçando a questão das interdições relacionadas à sexualidade. Para ela, ao observarmos essa literatura através do prisma da repressão sexual, os contos apresentam-se ambíguos. Isto se dá pois, ao mesmo tempo em que expressam teor lúdico e trazem a margem desejos e fantasias pertinentes à sexualidade infantil, possuem um lado pedagógico que acentua padrões de repressão.

A intervenção dos adultos também se mostra recorrente nos contos, uma vez que atuam de acordo com diversas normas e regras, entre elas a opção pelo mais fraco ou que possui senso de justiça. Em função disso, o conto passa a convencer a criança da importância de tais prescrições e do resultado através da desobediência no sofrimento. Assim sendo, a repressão caminha lado a lado com a ludicidade.

Os estereótipos são criados dessa maneira, a partir da relação binária entre masculino e feminino reforçada pela sociedade. Para Mendes (2000), encontramos tam- 
bém nessas narrativas reflexos da discrepância social, expressando o modelo da burguesia. Logo, além dos extremos entre homens e mulheres, a diferença entre classes sociais mostra-se presente.

A manutenção da representação feminina em papéis centrais se manteve apenas na condição de deusas, já que em outras situações os arquétipos femininos se apresentavam inferiores em relação aos masculinos. Mendes (2000) também nos mostra que Perrault, além de preservar os temas pertinentes à mitologia, propagava a ideologia familista da classe dominante.

Os arquétipos masculinos também ficam evidentes, por exemplo, por meio do príncipe corajoso, forte e bonito. Aqueles que não possuem esses atributos são condicionados ao sentimento de fracasso e exclusão perante os que comportam tais características. Além disso, o masculino está constantemente ligado à noção de felicidade e salvação em decorrência do matrimônio.

Em vista de todos os fatores expostos aqui, a leitura dos contos de fadas traduz sentimentos vivenciad os pelas crianças como as ansiedades, rivalidades, rejeições, medos etc. Assim, a forma de ver o mundo em que vivemos é expressa nessas narrativas. Elas podem, então, compreender muitas interpelações, por isso constituem e produzem sentidos e representações que atuam no imaginário social e simbólico.

Além das relações binárias do feminino e masculino, o conto de fadas remete a valores sociais, resultando dessa maneira em diversas discussões. Por esse motivo, a utilização dessas histórias no contexto escolar auxilia na psicologização e pedagogização dos alunos, não nos limitando apenas ao universo infantil, mas possibilitando também a extensão de seu emprego no ensino médio.

Ao reconhecermos nos contos de fadas a existência dessas questões e a presença de estereótipos é evidente a necessidade de reavaliação das formas pelas quais os contos serão apresentados aos alunos. 0 professor deve compreender que tais autores estavam inseridos em um determinado tempo e espaço histórico, tendo assim, visões de mundo relevantes àquela época.

Guimarães (1995) discorre também sobre o papel da escola quando afirma que essa instituição assume uma postura tradicionalmente conservadora e em alguns aspectos evidencia sua fragilidade em relação à inclusão da sexualidade no âmbito da escola. Verifica-se, por exemplo, a existência de pudores e preconceitos enraizados no espaço escolar quando o assunto é associado à orientação sexual.

A autora indica também que, uma vez que os professores se tornam modelos para os estudantes, muitas vezes esses adotam as opiniões expressas pelo educador, construindo seu repertório sobre a sexualidade embasado nesses conceitos. Isto enfatiza a necessidade de preparação do profissional da educação, pois além de refletir sobre seus próp rios valores, conceitos e preconceitos, deve possibilitar a esses estudantes um espaço de troca de conceitos, opiniões e crítica.

Ela acrescenta ainda que, ao defrontar-se com temas relacionados ao sexo, a escola geralmente também se mostra retrógrada em relação ao tempo presente. Isso se vê quanto às questões de gênero, pois estereótipos menosprezando mulheres, se comparados aos homens, são frequentemente acentuados nesses ambientes.

Quando voltamo-nos ao papel do professor diante de tais questões, sua importância mostra-se imprescindível, visto que seu contato é direto com os alunos, e 
assim é possível conhecer as dúvidas e inquietações dos mesmos. Por esse motivo, o educador pode tanto auxiliar ou esquivar-se na abordagem de temas relacionados à sexualidade. Como nos indica Leão (2009), ambas as atuações podem contribuir de forma favorável ou desfavorável em relação à educação sexual dos estudantes, haja vista que, ao invés de estimular o crescimento e amadurecimento dos mesmos, propagará estigmas.

\section{CONSIDERAÇÕES FINAIS}

Frente ao exposto, iniciativas inovadoras são fundamentais, pois propiciam, não só à escola como aos educadores, percorrer novos caminhos no ensino. Logo, a reflexão e recorrente desconstrução, levam o professor a repensar os usos comuns dos contos de fadas, atrelados normalmente ao ensino infantil e estabelece uma nova perspectiva sobre a utilização dos mesmos, uma vez que evidencia seu potencial como ferramenta para tratar das relações de gênero junto ao público adolescente do ensino médio. Por meio desse prisma, o ensino não se curva somente ao texto em si, mas a todas as facetas que esse possibilita. Sobre isso:

Portanto, se admitimos que a escola não apenas transmite conhecimentos, nem mesmo apenas os produz, mas que ela também fabricasujeitos, produz identidades étnicas, de gênero, de classe; se reconhecemos que essas identidades estão sendo produzidas através de relações de desigualdade; se admitimos que a escola está intrinsecamente comprometida com a manutenção de uma sociedade dividida e que faz isso cotidianamente, com nossa participação ou omissão; se acreditamos que a prática escolar é historicamente contingente e que é uma prática política, isto é, que se transforma e pode ser subvertida; e, por fim, se não nos sentimos conformes com essas divisões sociais, então, certamente, encontramos justificativas não apenas para observar, mas, especialmente, para tentar interferir na continuidade dessas desigualdades (LOURO, 1997, p. 85-86, grifos da autora).

Os contos de fadas, desse modo, devido à sua atemporalidade, poderão, além de exprimir e transmitir valores, reforçar ou criticar preconceitos, paradigmas e questões de gênero, pois por meio deles poderemos formar adultos críticos e conscientes de sua realidade. Abordando as situações encontradas nos contos de fadas como o racismo, machismo, sexismo e outras que perpetuem estigmas negativos, o professor terá em mãos uma ferramenta que possibilite observar a sociedade por meio de suas desigualdades e consequentemente, discutir através do confronto com essas raízes 0 reflexo que temos ainda hoje nas práticas sociais. 


\section{FAIRY TALES: PEDAGOGICAL STRATEGY TO MITIGATE FEMALE STEREOTYPES}

ABSTRACT: Sexuality is constructed through patterns of behavior and customs of mankind throughout the history, and various factors and results in you release or suppression. Fairy tales originated from orality and recounted over the centuries put the women constantly inferior to the men, naturalizing female vulnerability. In this view, this article of bibliographic nature sought to meet, describe and discuss what the scientific studies say about the use of short stories in high school, trying to analyze its use as a pedagogical strategy to mitigate the stereotypes of female inferiority and other prejudices. So, confirmed the assertiveness of this approach, since it can transmit values, strengthen or criticize paradigms and gender issues.

KEYWORDS: Fairy tales. Sexuality. Stereotype. Prejudice.

\section{CUENTOS DE HADAS: ESTRATEGIA PEDAGÓGICA PARA MITIGAR LOS ESTEREOTIPOS FEMENINOS}

RESUMEN: La sexualidad está hecha de patrones de comportamiento y costumbres de la humanidad a lo largo de la historia, y por diversos factores resulta en su liberación o represión. Ya los contos de hadas procedentes de la oralidad y recontados a lo largo de los siglos ponen las mujeres constantemente de forma tan inferior a los hombres, naturalizando la vulnerabilidad femenina. En vista de esto, este artículo de naturaleza bibliográfica buscó conocer, describir y discutir lo que dicen los estudios científicos sobre el uso de los cuentos en la escuela secundaria, tratando de analizar su uso como una estrategia pedagógica para mitigar los estereotipos de inferioridad femenina y otros prejuicios. Así se confirmó la asertividad de este enfoque, ya que puede transmitir valores, fortalecer o criticar paradigmas y temas de género.

PALABRAS CLAVE: Cuentos de hadas. Sexualidad. Estereotipo. Prejuicio.

\section{REFERÊNCIAS}

AUGUSTINI. E. R. do N. Contos de fadas no ensino fundamental l: analisando os recursos empregados e as estratégias que podem ser adotadas pelas/os docentes na desconstrução de estereótipos sexistas. 234 p. Dissertação (Mestrado em Educação Sexual). Faculdade de Ciências e Letras, Universidade Estadual Paulista, Araraquara, São Paulo, 2015.

CAMPBELL, J. O poder do mito. C. F. Moisés Trad. São Paulo: Palas Athena, 1990.

CASHDAN, S. Os 7 pecados capitais nos contos de fadas: como os contos de fadas influenciam nossas vidas. Rio de J aneiro: Campus, 2000.

CHAUÍ, M. Repressão sexual:essa nossa desconhecida. 4a ed. São Paulo: Brasiliense, 1984.

COELHO, N. N. O conto de fadas. 2ª ed. São Paulo, Editora Ática, 1991. 
CORSO, D. L. ; CORSO. M . Fadas no divã:psicanálise nas histórias infantis. Porto Alegre: Artmed, 2006.

GUIMARÃES, I. Educação sexual na escola:mito e realidade. Campinas, SP: Mercado de Letras, 1995.

JUNG, C. G. O Homem e Seus Símbolos. Rio de J aneiro: Nova Fronteira, 1976.

LEÃO, A. M. C. Estudo analítico-descritivo do curso de pedagogia da UnespAraraquara quanto a inserção das temáticas de sexualidade e orientação sexual na formação de seus alunos. 343 p. Tese (Doutorado em Educação Escolar). Universidade Estadual Paulista, Faculdade de Ciências e Letras, Campus de Araraquara, 2009.

LOURO, G. L. Gênero, sexualidade e educação: uma perspectiva pós-estruturalista. 6a ed. Petrópolis: Vozes, 1997.

MENDES, M. B. T. Em busca dos contos perdidos. 0 significado das funções femininas nos contos de Perrault. São Paulo: UNESP/ Imprensa Oficial do Estado de São Paulo, 2000.

NEUMANN, E. Amor e Psiquê:uma interpretação psicológica do conto de Apuleio. Trad. Zilda Hutchinson Schild. São Paulo: Cultrix, 1990.

PROPP, V. As raízes históricas do conto maravilhoso. 2a ed. São Paulo: Martins Fontes, 2002.

WEREBE, M. J. G. Sexualidade, política e educação. Campinas: Autores Associados, 1998.

Luciana Fernandes CimetTA: Graduanda em Letras Português/Espanhol pela Universidade Estadual Paulista Julio de Mesquita Filho, FCLAr - Araraquara.

E-mail: lucianafcimetta@smail.com

Andreza MARQues de CASTRO Leão: Professora doutora, mestra em Educação Especial pela UFSCar, doutora em Educação Escolar pela UNESP com Pós-Doutorado em Sexologia e Educação Sexual. Departamento de Psicologia na Faculdade de Ciências e Letras da UNESP, em Araraquara.

E-mail: andreza_leao@yahoo.com.br

Este periódico utiliza a licença Creative Commons Attribution 3.0, para periódicos de acesso aberto (Open Archives Iniciative - OAI). 